\title{
Crianças em passagem: um caminho para a cidadania?
}

\author{
Children passing through public \\ foster care: a way to social development?
}

\author{
Cristhiane de Araújo Torres ${ }^{1}$ \\ José de Santana Neto ${ }^{1}$ \\ Mayara Mytzi de Aquino Silva \\ Thiago Roberto Maciel Grossi \\ Leonardo Moura Ferreira de Souza ${ }^{2}$ \\ Nadja S. P. D. Rocha
}

\section{Resumo}

O objetivo do trabalho foi analisar aspectos psicossociais relevantes no comportamento e na saúde das crianças institucionalizadas em Casa de Passagem, além de observar as interferências psicológicas, sociais e educacionais que a institucionalização pode promover. O estudo foi realizado em dois momentos, com o intuito de analisar o funcionamento institucional e as condições atuais e pregressas dos usuários. No primeiro momento, foram realizados exame clínico para avaliação de condições gerais de saúde e perfil nutricional, além de desenho com tema livre a fim de fornecer dados psicoafetivos. No segundo momento, desenvolveu-se ação lúdica para apresentação de teatro de fantoches com temática educativa. Do ponto de vista institucional, a Casa de Passagem está organizada em conformidade com os objetivos de seu projeto de criação. O perfil geral das crianças revelou um predominância de meninos, entre oito e 11 anos de idade e abrigados há menos de um ano. Uma porcentagem significativa de crianças ignorava seu nome completo, sua idade, o nome de seus pais, a série que cursavam e os dias do mês e da semana em que se encontravam. Isso sugeriu uma situação de desorientação, descaso individual e a falta de vínculo e apoio familiar. Foi possível compreender o papel crucial da família na formação do indivíduo influenciando desde o comportamento, aspectos psicológicos, nutricionais, entre outros. Qualquer quebra na estrutura familiar pode prejudicar o crescimento e a formação da criança.

\begin{abstract}
The objective of this study was analyzing the social aspects that interfered with the behavior and healtby development of the children residing in a public institution, besides observing the psychological, social and educational interferences such a refuge can produce.

Palavras-chave: Saúde da Criança Institucionalizada;

Cuidado da Criança; Família - psicologia.

Key Words: Health of Institucionalized Children;

Child Care; Family - psychology.

\footnotetext{
Acadêmicos de medicina, Faculdade de Medicina, Universidade Federal do Rio Grande do Norte, Natal, Rio Grande do Norte, Brasil.

${ }^{2}$ Professor colaborador, médico pediatra, Faculdade de Medicina, Universidade Federal do Rio Grande do Norte, Natal, Rio Grande do Norte, Brasil. ${ }^{3}$ Médica pediatra, professora do Departamento de Pediatria, Faculdade de Medicina, Universidade Federal do Rio Grande do Norte, Natal, Rio Grande do Norte, Brasil.
} 
The study was conducted in two moments aimed at analyzing the performance of the institution and the conditions of the children before and after admission. First, the children were submitted to a physical examination and establishment of their nutritional profile. The children were allowed to draw something of their own choice in order to obtain clues about their psycho-emotional condition. There was a relax moment in the form of an educative puppet show to observe the children's spontaneity.

The institution sheltered more boys than girls. The mean age was 8-11 years and the time of permanence in the institution was less than one year. A great part of the children ignored their full name, their age, the names of their parents, the grade they attended at school and even the day of the week and the current month. This situation suggests disorientation, indifference and a lack of support of their families.

The study showed clearly the crucial role of the family in the formation of the individual, among others influencing behavioral, psychological and nutritional aspects. Any rupture in the family structure can harm the child for the rest of the life.

\section{Introdução}

A família, segundo a legislação brasileira, é a única estrutura vital para humanização e socialização da criança e do adolescente. No entanto, com a crise socioeconômica e a desestruturação familiar, torna-se necessária a intervenção do Estado por meio da privação da criança em risco social do convívio familiar nocivo e do seu abrigo em instituições. Entretanto, todos os esforços devem ser empreendidos no sentido de reinserir a criança ou o adolescente no seu grupo familiar original. As Casas de Passagem são instituições públicas municipais destinadas ao abrigo temporário e à ressocialização dessas crianças.

A importância do ambiente no desenvolvimento da criança é notória na vinculação afetiva e, para Keenan ${ }^{1}$, seria a responsável pelo estabelecimento na criança da confiança e da segurança para explorar e apreender o mundo. Ainsworth et $\mathrm{al}^{2}$. foram pioneiras ao estudarem os diferentes tipos de apego que uma criança pode desenvolver. Assim, a criança possui apego inseguro quando suas mães são insensíveis ou negligentes às suas necessidades. Este comportamento não desenvolve na criança a confiança que ela deve ter em si e nos outros. Por outro lado, quando ocorre o atendimento de suas necessidades de afeto, trocas subjetivas e cuidados de higiene e alimentação, a criança se torna confiante e pode ter um saudável desenvolvimento de suas capacidades física, emocional e intelectual.

O cuidador é o mediador de muitos comportamentos que a criança desenvolverá, regulando sua atenção, curiosidade, cognição, linguagem, emoções, dentre outros ${ }^{3}$. Portanto, para este estudioso, a criança que vive em instituição, sem a presença de uma pessoa significativa, poderá ter seu desenvolvimento prejudicado, por ter sido privada, total ou parcialmente, de se vincular afetivamente com alguém que lhe ofereça apoio, proteção e cuidados ${ }^{4}$.

É importante destacar a influência da institucionalização sobre as crianças. Os estudos realizados por Tizard $\&$ Tizard $^{5}$ revelam, por outro lado, que os efeitos adversos do abrigamento não provêm da separação da mãe, mas da qualidade da instituição na qual a criança é deixada. Segundo os autores, aquelas instituições que oferecem baixa proporção entre adulto e criança, condições de saúde, higiene e estimulações físicas e emocionais podem favorecer o desenvolvimento e não o prejudicar.

A despeito de muitas crianças vivenciarem situações de estresse e risco em seu cotidiano, podendo apresentar distúrbios emocionais e problemas de conduta, nem todas apresentam estes comportamentos ${ }^{6}$. Pelo contrário, algumas delas conseguem adaptar-se e superar essas situações, demonstrando, entre outras habilidades, competência social, manifestando o que se denominou resiliência, isto é, uma capacidade de se sair bem frente a fatores potencialmente estressores $^{7,8}$. Assim, é importante estabelecer um forte e constante vínculo afetiva com a criança, a fim de lhe proporcionar um saudável desenvolvimento físico, psíquico e social. Isto se torna ainda mais relevante com crianças desprovidas de pessoas significativas em suas vidas e obrigadas a viver institucionalizadas à espera de adoção ou, quando possível, retorno à família de origem, enfim, de alguém que supra suas necessidades. 
O Levantamento Nacional de Abrigos para Crianças e Adolescentes (Silva, 2004) encontrou cerca de 20 mil crianças e adolescentes vivendo em 589 abrigos pesquisados no Brasil, sendo na sua maioria meninos na faixa de idade de 7 e 15 anos, negros e pobres. Os dados mostraram ainda que $87 \%$ das crianças e adolescentes abrigados têm família, sendo que 58\% mantêm vínculo com seus entes. Contudo, foi também constatado que o tempo de duração da institucionalização pode variar até um período de mais de 10 anos. $^{9}$

O objetivo principal do estudo foi analisar aspectos psicossociais relevantes no comportamento e na saúde das crianças institucionalizadas na Casa de Passagem II. Por meio do estudo foi possível ainda: identificar o perfil nutricional, clínico e psicoafetivo das crianças acolhidas na casa de passagem; caracterizar o perfil de funcionamento da instituição; identificar os principais motivos que levam as crianças a serem abrigadas; obter das crianças a sua visão sobre a casa de passagem; realizar planos terapêuticos voltados para os principais agravos identificados no perfil, com os respectivos encaminhamentos médicos, odontológicos e psicológicos.

\section{Métodos}

O estudo foi realizado com cerca de 23 crianças de 7 a 11 anos, institucionalizadas na Casa de Passagem II, no município de Natal, $\mathrm{RN}$, durante o período do internato médico em pediatria, através de visitas à instituição. A análise foi dividida em dois momentos distintos. No primeiro, foi realizada entrevista com a equipe multidisciplinar, que respondeu a um questionário (perguntas abertas e fechadas) com o intuito de traçar o perfil institucional da casa. Foram realizados desenhos e pinturas (temas livres) com o propósito de posterior análise dos dados aspectos psicoafetivos das crianças. Foi respondido ainda, pelas crianças, um questionário dirigido (perguntas abertas e fechadas). Procurouse, traçar o perfil pediátrico - clínico e nutricional - por meio do preenchimento de uma ficha individual, com dados de identificação: nome, idade, peso, dentre outros. Foram realizados exame físico sumário e observação do padrão nutri- cional, afecções dermatológicas, odontológicas, entre outras. De acordo com as necessidades, as crianças foram encaminhadas para especialistas e odontólogos. Foram realizados exames laboratoriais e radiografias específicas, de mão e punho direitos, para investigação de retardo do crescimento.

No segundo momento, foi realizada atividade lúdica caracterizada por um teatro de fantoches, objetivando informação, educação e comunicação a partir da abordagem do tema parasitoses intestinais, dada sua alta prevalência identificada no perfil de morbidade do grupo.

A obtenção dos resultados foi feita, primeiro, pela tabulação dos dados adquiridos por meio da aplicação dos questionários dirigidos, separando as variáveis de acordo com o perfil analisado. Primeiro, foi feito o agrupamento dos dados referentes ao perfil institucional da Casa de Passagem II, o qual continha informações sobre sua data de criação, tempo de funcionamento, localização atual, equipe, objetivos, estrutura, público-alvo, órgão responsável, rotina da casa, protocolo para a institucionalização da criança, atividades "extra-Casa de Passagem II" e lazer.

No perfil da criança, englobaram-se os dados referentes ao conhecimento sobre suas familias, orientação temporal, opinião aberta sobre a instituição, atividade escolar e dados pessoais - como idade e nome completo. Foi estabelecido também um perfil da saúde, com análise dos dados relativos ao exame físico sumário, incluindo o estado nutricional, além da quantidade e tipo de encaminhamento médico, e, ainda, variáveis, como quantidade e tipo de encaminhamento médico.

Para todas as variáveis, foram calculadas, utilizandose o programa Excel ${ }^{\circledR}$, as porcentagens referentes a cada resposta possível dada pelas crianças com a posterior elaboração de gráficos com base, unicamente, nos dados encontrados no questionário dirigido, exame físico sumário e encaminhamentos.

A avaliação desse aspecto foi realizada com base na análise dos desenhos individuais confeccionados pelas crianças no momento lúdico 1. Tal análise foi desenvolvida por uma equipe multiprofissional (psicóloga, assistente social 
e pedagoga) da própria instituição, capaz de contextualizar o desenho na condição psicoafetiva de cada criança de acordo com a sua realidade pregressa e atual. Ao final, foram emitidos pareceres conclusivos individuais e um parecer geral.

\section{Resultados}

Os motivos para o abrigo mais comumente citados foram: violência doméstica e/ou maus-tratos; mendicância; negligência dos pais; pais falecidos; pais envolvidos com drogas; pais em regime de prisão; abandono do lar pelas crianças e abuso sexual.

$\mathrm{Na}$ análise do percentual de meninos ou meninas na Casa de Passagem II, podemos observar uma prevalência de meninos (68\%) em detrimento das meninas (32\%). Esse achado está em acordo ao encontrado em outras Casas de Passagem no Brasil.

Com relação à idade média das crianças, o que foi observado é que a maioria delas se encontra entre os 10 anos e 10 anos e 11 meses (28\%) e entre os 8 anos e 8 anos e 11 meses (20\%). Esses dois grupos somados chegam a quase metade das crianças da Casa de Passagem II.

No quesito tempo de permanência, observamos nítida prevalência das crianças que se encontram há menos de um ano na instituição (84\%).

Quando questionadas as razões pelas quais essas crianças se encontram na Casa de Passagem II, as quatro principais, em ordem decrescente de valor percentual foram: mendicância (28\%); abandono dos pais (20\%); maustratos $(20 \%)$; negligência (16\%). Não devemos, no entanto, nos esquecer de que essa diferenciação é muito tênue, pois a alegação de mendicância certamente abrange crianças que, na verdade, foram abandonadas pelos pais ou simplesmente negligenciadas ou mesmo receberam maus-tratos e procuraram "as ruas" para se protegerem.

Perguntas a respeito do próprio nome, idade, nome do pai, nome da mãe, quantidade de irmãos foram direcionadas às crianças, encontrando-se os seguintes resultados: $96 \%(\mathrm{n}=24)$ das crianças souberam o seu nome completo por extenso, enquanto $4 \%(n=1)$ não souberam responder. Em relação à idade, 56\% $(n=14)$ responderam corretamente a idade, $40 \%(\mathrm{n}=10)$ responderam, mas de forma equivocada, e 4\% $(n=1)$ não souberam responder (Gráfico 1). Esses resultados mostram a fragilidade como indivíduo dessas crianças pelo não-reconhecimento da própria idade, mostrando-se alheios às mudanças corporais e à noção de identidade, podendo isso repercutir em seu futuro, em vista que estão em sua formação de personalidade, mas não conseguem ainda se perceber como indivíduos.

Quando perguntadas sobre o nome do pai e da mãe, 93\% (n=23) e 88\% ( $\mathrm{n}=22)$ souberam responder corretamente, respectivamente. Sendo que $8 \%(n=2)$ não souberam ou não responderam ao questionamento sobre o nome do pai, e $12 \%(n=3)$ não souberam ou não responderam a respeito do nome da mãe.

A orientação temporal foi avaliada mediante pergunta a respeito de qual era o dia da semana no momento do questionário, obtendo-se o seguinte resultado: $44 \%(\mathrm{n}=11)$ não sabiam em que dia da semana se encontravam, 24\% $(n=6)$ responderam, mas não acertaram a pergunta, $28 \%(n=7)$ responderam corretamente, e $4 \%$ $(\mathrm{n}=1)$ não responderam ao questionamento (Gráfico 2). Essa falta de orientação temporal poderia ser justificada pelo confinamento excessivo que se impõe às crianças.

Das crianças abrigadas na Casa de Passagem II, $76 \%(\mathrm{n}=19)$ sabiam o real motivo de estarem no local, $12 \%(n=3)$ não sabiam o motivo e $12 \%(n=3)$ não responderam ao questionamento. A opinião das crianças abrigadas foi favorável em $56 \%(\mathrm{n}=14)$ do total, $36 \%(\mathrm{n}=9)$ desfavorável, e $8 \%(\mathrm{n}=2)$ não responderam à pergunta. Com relação à vontade das crianças em regressarem para suas casas, $80 \%(n=20)$ responderam que gostariam de voltar para casa, enquanto $20 \%(n=5)$ optaram por não voltarem.

Em relação à saúde geral das crianças na Casa de Saúde II, segundo avaliação por exames físicos sumários realizados, encontrou-se um elevado número de lesões dérmicas $(64 \%)$, as mucosas estavam normais em sua maioria (84\%), e, quando alteradas, a palidez era a maior alteração; a higiene dentária foi avaliada como "precária" 
em 52\% das crianças. Dos exames complementares solicitados, o de raios-x de punho e mãos foi solicitado em 24\% das crianças, e o hematócrito em 16\%. Dos exames de imagem solicitados, 67\% se revelaram incompatíveis com a idade cronológica, com diferença superior a dois anos, sendo que, nos extremos, essa diferença foi de cinco anos.

$\mathrm{Na}$ avaliação do percentil do peso (gráfico 3), podemos observar que a maioria das crianças abrigadas encontrava-se dentro da faixa da normalidade; $96 \%$ se encontravam entre o percentil 2,5 e o 90 , e apenas $4 \%$ se encontravam acima do P97,5. Do total de crianças, cerca de $20 \%$ se encontravam entre os $\mathrm{P} 10$ e P2,5, necessitando, portanto, de maior cuidado em avaliações futuras.

A análise da estatura (gráfico 4) se mostrou mais preocupante devido ao grande percentual de crianças que se encontrava no patamar inferior ao P2,5 (24\%). Apesar de $50 \%$ das crianças se manterem entre o P10 e P90, um número significativo de crianças se manteve no grupo entre P2,5 e P10, que, apesar de não significarem alterações patológicas, necessitam de maior atenção no seguimento ponderal.

\section{Discussão}

Conhecer o funcionamento da instituição foi extremamente esclarecedor, além disso, saber as dificuldades por que passam estas crianças serviu de base para a compreensão das limitações do serviço e de estímulo para ações voluntárias e parcerias.

Os resultados do trabalho permitiram conhecer um perfil geral das crianças institucionalizadas: sexo masculino, idade entre oito e 10 anos, anêmico, portador de lesões dermatológicas e de algum grau de desnutrição aguda ou pregressa.

No entanto, mais do que os dados clínicos já parcialmente previstos, o contato permitiu conhecer uma visão mais realista da vida desses indivíduos e contribuiu para um novo enfoque na formação profissional dos futuros médicos integrantes do estágio de pediatria e participantes do trabalho.
A resolução do problema passa por questões sociais, econômicas e educacionais. Atuações pontuais do Estado não são suficientes para resolução deste complexo panorama. Ao mesmo tempo, a intervenção social e filantrópica precisa ser fortalecida para ajudar no processo de reinserção familiar para aquelas que tiverem condições de retornar ou na obtenção de outras famílias para aquelas crianças que não possuem condições de reinserção. Os mecanismos jurídicos para adoção ainda são entraves importantes do processo de ressocialização dessas crianças, principalmente pela lentidão burocrática e o tempo gasto para que o processo jurídico seja efetivado. Assim, muitas vezes, quando são adotadas, já passaram muitos anos da infância abrigadas nas instituições e adquirem permanentes seqüelas sociais, que não serão mais revertidas. Outras vezes, as famílias que estão interessadas na adoção acabam desistindo diante de tantos obstáculos judiciais.

No final do estudo, foram firmadas com a Casa de Passagem II parcerias estabelecidas entre instituições de ensino-serviço, com o intuito de garantir, de forma contínua, a assistência médica e odontológica às crianças abrigadas, aliada à consolidação de um novo enfoque humanista na formação da graduação. 
Gráfico 1. Conhecimento das crianças a respeito da própria idade:

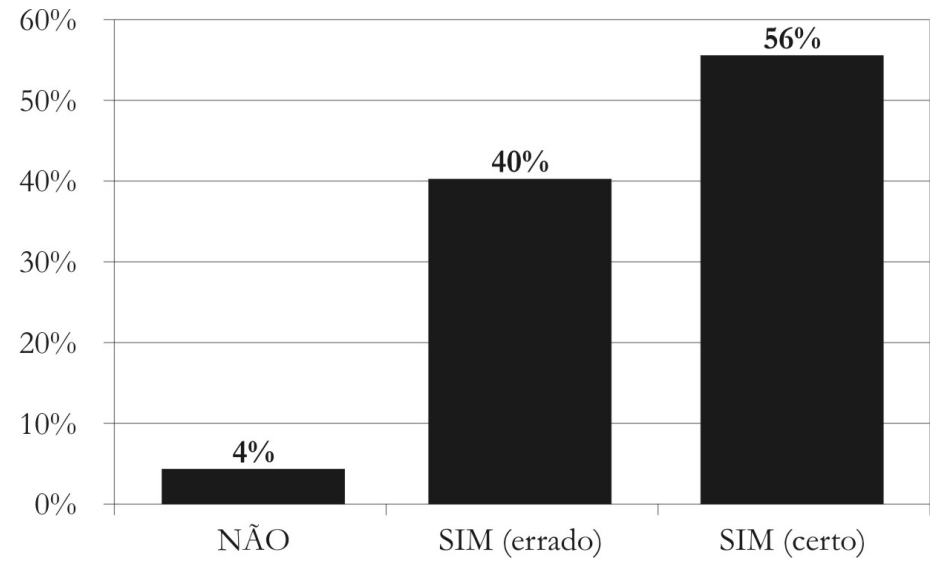

Gráfico 2. Orientação temporal das crianças a respeito do dia da semana:

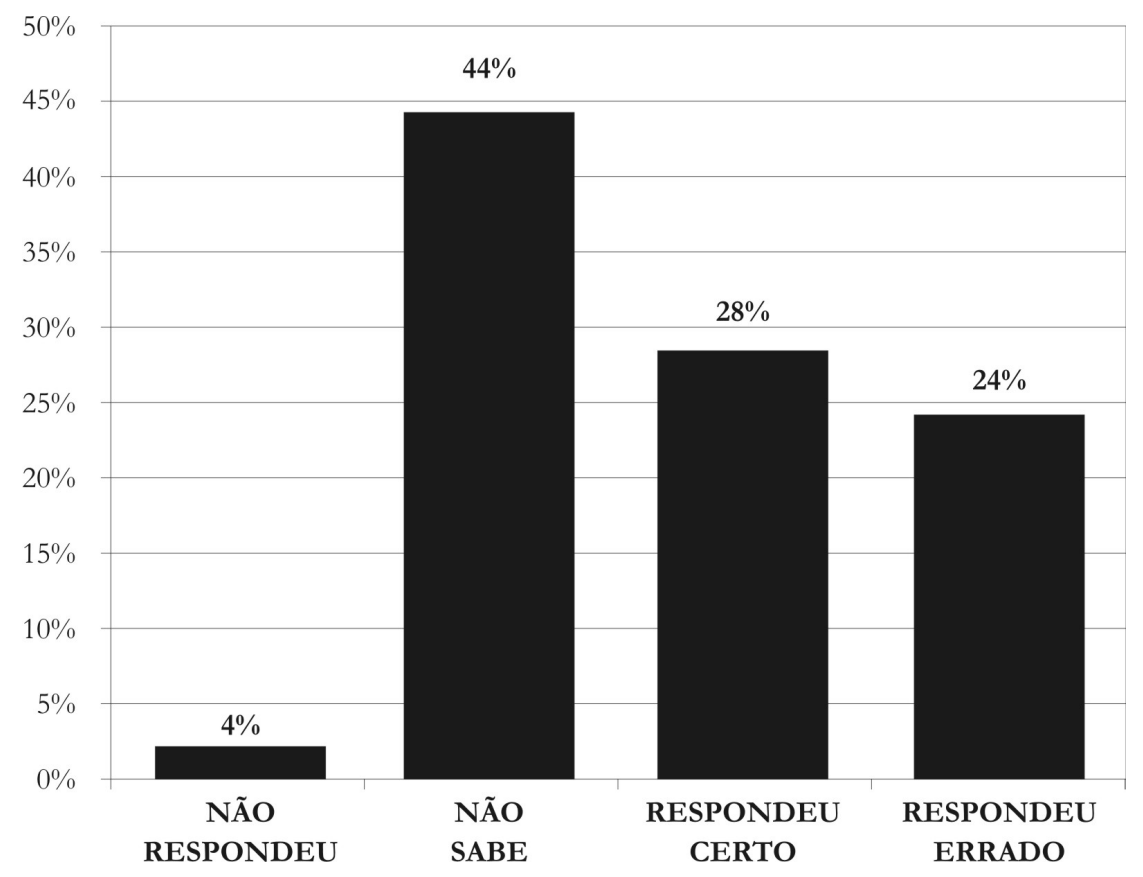


Gráfico 3. Percentil do peso das crianças abrigadas:

\section{PERCENTIL DO PESO}

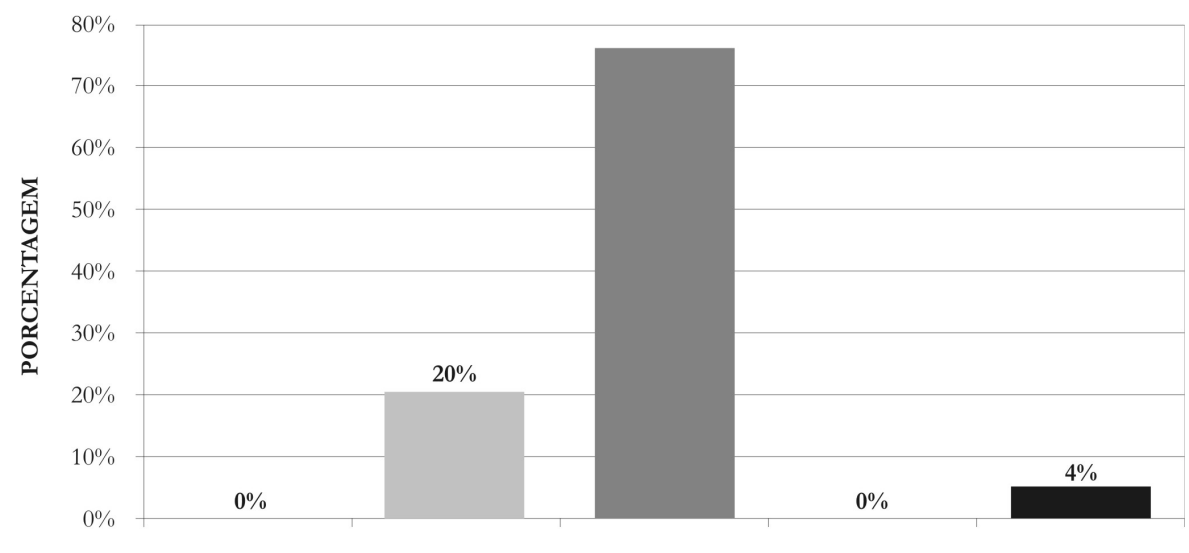

PERCENTIS

$\square$ P<2.5 $\square$ P 2.5-10 $\square$ P 10-90 $\square$ P 90-97.5 $\square$ P >97.5

Gráfico 4. Percentil por estatura das crianças abrigadas:

\section{PERCENTIL POR ESTATURA}

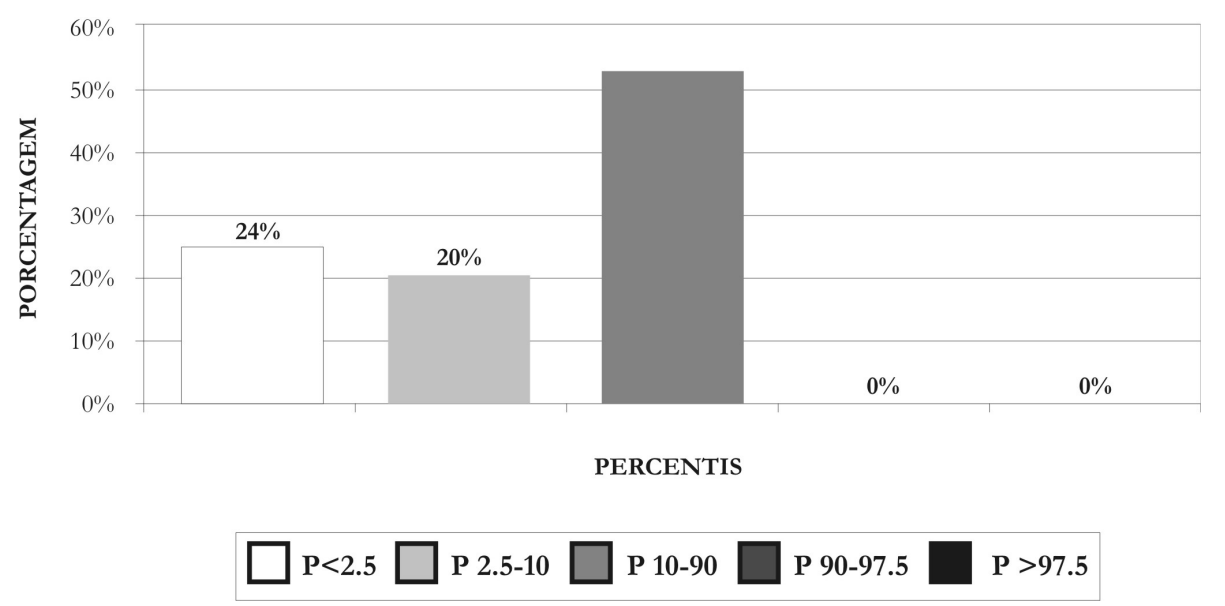




\section{Referências}

1. Keenan T. An introduction to child development. London: Sage Publications; 2002.

2. Ainsworth MDS, Bell SMV, Stayton DJ. Individual differences in strange-situation behavior of one-year-olds. In: Schaffer HR, editor. The origins of human social relation. London: Academic Press; 1971. p. 17-57.

3. Stern D. O mundo interpessoal do bebê. Porto Alegre (RS): Artes Médicas; 1992.

4. Bowlby J. Cuidados maternos e saúde mental. São Paulo: Martins Fontes; 1995.

5. Tizard J, Tizard B. The social development of twoyearold children in residential nurseries. In: Schaffer HR, editor. The origins of human social relation. London: Academic Press; 1971. p. 147-160.

6. Cecconello AM, Koller SH. Competência social e empatia: um estudo sobre resiliência com criança em situação de rua. Est Psico (Natal) 2000; 5(1):71-93.

7. Kotliarenco MA, Cáceres I, Fontecilla M. Estado de arte en resiliencia. Washington, D.C.: Organización Panamericana de la Salud; 1997.

8. Munist M, Santos H, Kotliarenco MA, Ojeda ENS, Infante F, Grotberg E. Manual de identificación y promoción de la resiliencia. Washington, D.C.: Organización Panamericana de la Salud; 1998.

9. Siqueira AC, Dell'Aglio DD. O Impacto da Institucionalização na Infância e na Adolescência: Uma Revisão de Literatura. Psicologia \& Sociedade. Jan.-Abr. 2006; 18 (1): 71-80.

\section{Endereço para correspondência:}

Rua Francisco Pignataro, 1955

Natal (RN)

CEP: 59082070.

\section{Endereço eletrônico:}

cristhiane_torres@hotmail.com 